\title{
Formalização estratigráfica do Membro Fundão, Formação Rio da Batateira, Cretáceo Inferior da Bacia do Araripe, Nordeste do Brasil
}

\author{
Aristóteles de Moraes Rios-Netto ${ }^{1^{*}}$, Alexandre Braga Leal de Paula-Freitas ${ }^{2}$, Ismar de Souza \\ Carvalho $^{3}$, Marília da Silva Pares Regali ${ }^{4}$, Leonardo Borghi ${ }^{5}$, Francisco Idalécio de Freitas ${ }^{6}$
}

\begin{abstract}
Resumo O intervalo litoestratigráfico conhecido como "camadas Batateira" é bastante citado na literatura sobre a Bacia do Araripe, tendo sido reconhecido tanto na Sub-bacia do Cariri, quanto na Sub-bacia de Feitoria. Sua ampla distribuição e, aparentemente, pouca espessura, levaram-no a ser considerado um marco de correlação regional. No entanto, apesar da importância que lhe é atribuída, o intervalo nunca foi alvo de uma descrição formal, o que levou o nome "camadas Batateira" a ser utilizado com abrangência variada entre os diversos autores, tornando urgente sua discussão e formalização. Análises litoestratigráficas, palinológicas e do conteúdo de carbono orgânico total do furo de sondagem 1-PS-06-CE e sua correlação com o afloramento no Rio Batateira (citado originalmente como seção de referência do intervalo) permitiram uma caracterização mais precisa do intervalo e uma proposta de formalização sob a denominação de "Membro Fundão", com a definição de holoestratótipo, representado pelo afloramento no Rio Batateira (localidade do Sítio Fundão, município do Crato, Ceará), e de um estratótipo suplementar, constituído por testemunhos do furo de sondagem 1-PS-06-CE (localidade de Salobro, município de Abaiara, Ceará).
\end{abstract}

Palavras-chave: Bacia do Araripe; Cretáceo Inferior; litoestratigrafia; Formação Rio da Batateira; Membro Fundão; camadas Batateira.

\begin{abstract}
Fundão Member - Proposal of a formal subdivision of Rio da Batateira Formation, Lower Cretaceous of Araripe Basin, Northeastern Brazil. The lithostratigraphic unit known as "Batateira beds" is often cited in the literature on the geology of the Araripe Basin. This interval was already recognized both in the Cariri Sub-basin and in the Feitoria Subbasin. It has been considered a datum for regional correlation, due to its basin-wide occurrence and, apparently, reduced thickness. However, despite the importance assigned to it, the interval was never formally described, which led the name "Batateira beds" to be used with distinct meanings, making urgent the discussion and formalization of the interval. Lithostratigraphic, palynological and total organic carbon analyses on the borehole 1-PS-06-CE and its correlation with an outcrop in the Batateira river margin (originally cited as a reference section of the interval) allowed a more precise characterization and a formal proposal of the interval, under the name "Fundão Member", with the establishment of a holostratotype, represented by the outcrop in Batateira river (Sítio Fundão, Crato, Ceará State, Brazil), and a supplementar stratotype, composed of cores from the borehole 1-PS-06-EC (Salobro village, Abaiara, Ceará State, Brazil).
\end{abstract}

Keywords: Araripe Basin; Lower Cretaceous; litostratigraphy; Rio da Batateira Formation; Fundão Member.

INTRODUÇÃO Em meio a um espesso pacote de arenitos da Formação Rio da Batateira, no Cretáceo Inferior da Bacia do Araripe, destaca-se um intervalo composto predominantemente por folhelhos cinza escuro a negros, com breve intercalação de calcário ou marga, conhecido como "camadas Batateira", que tem sido reconhecido tanto na Sub-bacia de Feitoria (Oeste) quanto

\footnotetext{
${ }^{1}$ Laboratório de Bioestratigrafia e Paleoecologia - LabMicro, Departamento de Geologia, Instituto de Geociências, Universidade Federal do Rio de Janeiro - UFRJ, Brasil. E-mail: rios.netto@geologia.ufrj.br

${ }^{2}$ Laboratório de Geologia Sedimentar - LAGESED, Departamento de Geologia, Instituto de Geociências, Universidade Federal do Rio de Janeiro - UFRJ, Brasil. E-mail: alebpl@gmail.com

${ }^{3}$ Departamento de Geologia, Instituto de Geociências, Universidade Federal do Rio de Janeiro - UFRJ, Brasil. E-mail: ismar@ geologia.ufrj.br

${ }^{4}$ Laboratório de Bioestratigrafia e Paleoecologia - LAGESED, Departamento de Geologia, Instituto de Geociências, Universidade Federal do Rio de Janeiro - UFRJ, Brasil. E-mail: regali.msp@gmail.com

${ }^{5}$ Laboratório de Geologia Sedimentar - LAGESED, Departamento de Geologia, Instituto de Geociências, Universidade Federal do Rio de Janeiro - UFRJ, Brasil. E-mail: lborghi@geologia.ufrj.br

${ }^{6}$ Universidade Regional do Cariri - URCA, Geopark Araripe, Crato (CE), Brasil. E-mail: idalecio@geoparkararipe.org

*Autor correspondente
} 
na do Cariri (Leste). Embora haja poucos trabalhos dedicados especificamente a esse intervalo (Farina 1974, Hashimoto et al. 1987, Assine et al. 2006), ele é frequentemente citado na literatura geológica e sua importância reside nas seguintes observações: (a) por apresentar características litológicas facilmente distinguíveis dos intervalos adjacentes e ser relativamente pouco espesso, o intervalo serve como datum para correlação intrabacial, fato que assume importância especial em uma bacia de arquitetura complexa como a do Araripe, estruturada em vários blocos deslocados verticalmente em grabens e horsts; (b) o intervalo representa o primeiro episódio de implantação de um amplo sistema lacustre durante a idade Alagoas na Bacia do Araripe - ainda que de duração relativamente curta -, o que ocorreu após um longo predomínio fluvial, representado pelas formações Missão Velha, Abaiara e Rio da Batateira (parte inferior). Mais tarde, um extenso ambiente lacustre-marinho se consolidaria na Bacia do Araripe, no tempo de deposição da Formação Santana.

Este trabalho se propõe a contribuir com o entendimeto de tal intervalo, o qual foi estudado sob os aspectos litoestratigráfico e do conteúdo palinológico e de carbono orgânico total, visando sua melhor caracterização. Os resultados levaram a uma proposta de formalização do intervalo.

CONTEXTO REGIONAL A Bacia do Araripe está localizada no interior do Nordeste do Brasil, abrangendo partes dos estados do Ceará, Pernambuco e Piauí. Tem orientação geral LesteOeste, estando limitada, aproximadamente, pelas coordenadas $38^{\circ} 35^{\prime}-40^{\circ} 50 \mathrm{~W}$ e $7^{\circ} 04^{\prime}-7^{\circ} 50^{\prime} \mathrm{S}$. Ocupa uma área de aproximadamente $12.200 \mathrm{~km}^{2}$, com extensão máxima aproximada de $250 \mathrm{~km}$, na direção Leste-Oeste, e 68 km, Norte-Sul (Fig. 1). A bacia insere-se na zona transversal da província estrutural Borborema, área marcada por diversos falhamentos presentes no embasamento pré-cambriano, com orientação predominante NordesteSudoeste e subordinada Noroeste-Sudeste (Ponte \& Ponte-Filho 1996, Matos 1992). Essa herança originou uma configuração em altos (horsts) e baixos (grabens) estruturais, os quais caracterizam sua arquitetura. Uma das manifestações dessa herança estrutural é a compartimentação da Bacia do Araripe em duas sub-bacias, separadas pelo horst

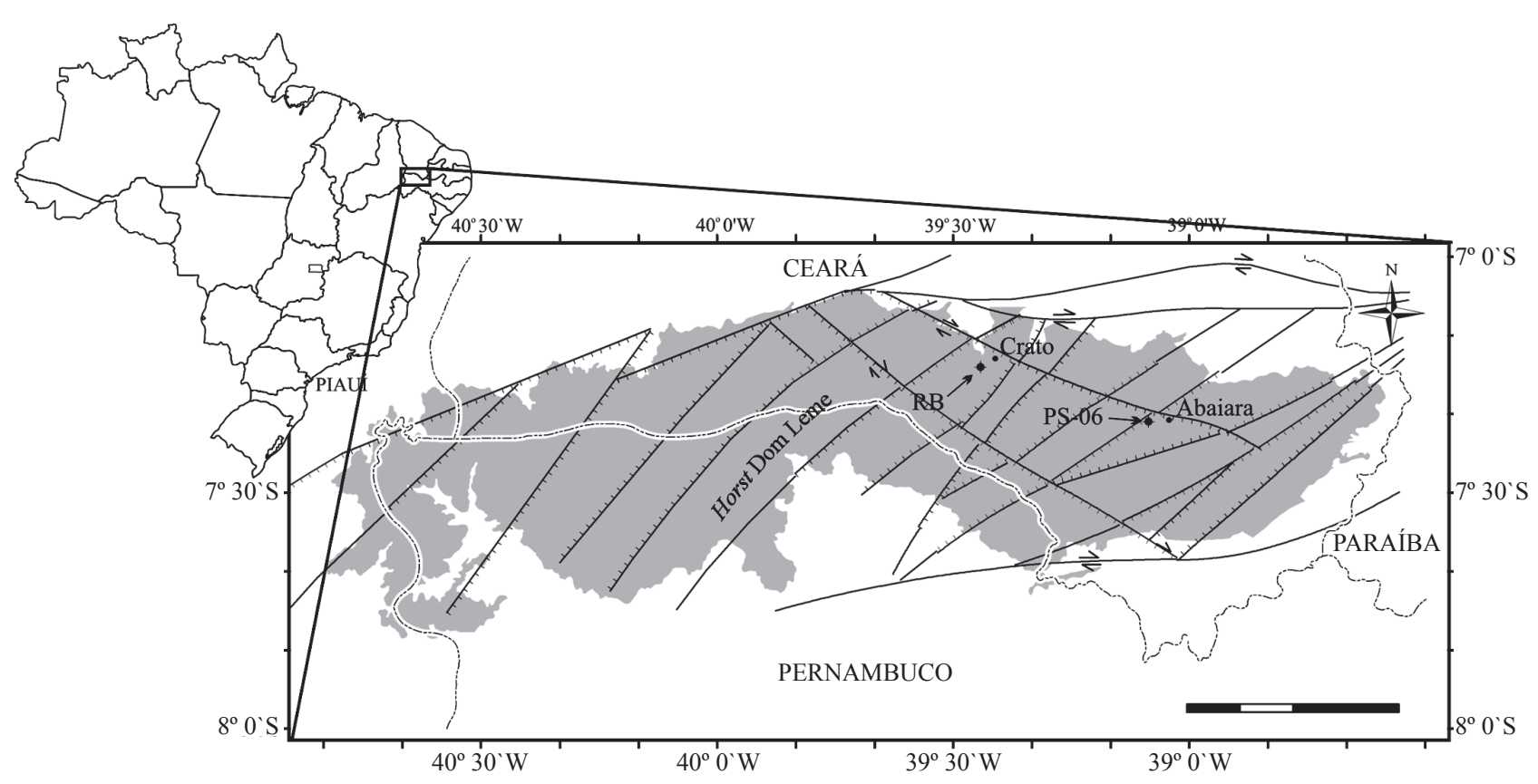

Figura 1-Mapa da Bacia do Araripe, mostrando as principais estruturas, o posicionamento do furo de sondagem (PS-06 = 1-PS-06-CE) e do afloramento (RB = Rio Batateira) estudados, além das cidades mais próximas a esses pontos. A Sub-bacia do Cariri, a Leste do horst Dom Leme, é fortemente marcada por uma calha estrutural de orientação aproximada Oeste-Noroeste-Leste-Sudeste (modificado de Ponte \& Ponte-Filho, 1996). 
Dom Leme: a de Feitoria, a Oeste dessa estrutura, e do Cariri, ao Leste (Fig. 1).

\section{ESTRATIGRAFIA DA BACIA, FORMAÇÃO RIO DA BATATEIRA E INTERVALO} ESTUDADO Diversos esquemas estratigráficos para a Bacia do Araripe foram apresentados desde a proposta pioneira de Small (1923), dentre os quais pode-se citar: Beurlen (1962, 1963, 1971), Braun (1966), Moraes et al. (1976), Ponte \& Appi (1990), Assine (1992, 2007), Martill \& Wilby (1993) e Neumann \& Cabrera (1999). Em uma visão geral, a coluna sedimentar da Bacia do Araripe é composta pelas formações Mauriti (ou Cariri), Brejo Santo, Missão Velha, Abaiara, Rio da Batateira (ou Barbalha), Santana (cujos membros alguns autores consideram como três formações distintas), Arajara e Exu.

A Formação Rio da Batateira - unidade na qual se insere o intervalo que é alvo deste trabalho - foi proposta por Ponte \& Appi (1990), tendo como seção-tipo a sequência que aflora nos barrancos das margens do Rio Batateira, entre os bairros Batateira e Lameiro, na cidade do Crato, Ceará (para a correta designação do referido acidente geográfico, veja o mapa planimétrico da folha SB24-Y-D-III - "Crato", editado pela Secretaria de Recursos Hídricos do Estado de Pernambuco).

Assine $(1990,1992)$ propôs para esse mesmo intervalo a denominação "Formação Barbalha", argumentando que o termo "Batateira" já havia sido utilizado por Hashimoto et al. (1987) para compor o nome "camadas Batateira". Deve-se lembrar, inicialmente, que a publicação de Assine (1990) é uma tese de doutoramento, um meio de divulgação explicitamente vedado pelo Guia de Nomenclatura Estratigráfica (Petri et al. 1986b, p. 406) para formalização de unidades estratigráficas; por outro lado, apesar da proposta de Ponte \& Appi (1990) não ter sido veiculada em periódico ou livro, foi publicada como trabalho completo em anais de um evento regular e de prestígio internacional (Congresso Brasileiro de Geologia), o que constitui um meio de divulgação científica de ampla tiragem e circulação, e, portanto, válido para formalização de unidades, segundo o Guia de Nomenclatura Estratigráfica (Petri et al., 1986b, p. 406).

Observa-se, ainda, que Hashimoto et al. (1987, p. 119) fizeram, assumidamente, apenas uma proposição informal: “[...] tais camadas são aqui, informalmente, denominadas 'camadas Batateira"". Desse modo, a proposta formal de Ponte \& Appi (1990 - "Formação Rio da Batateira") tem prioridade tanto sobre aquela apresentada por Hashimoto et al. (1987 - "camadas Batateira"), quanto sobre as de Assine (1990, 1992 - "Formação Barbalha). Outro ponto que se deve destacar é que Chagas et al. (2007, p. 314), em sua explanação do problema nomenclatural dessa formação, citam erroneamente os trabalhos de Assine (1990) e Ponte \& Appi (1990), quando escrevem que "[...] em ambos os trabalhos foi proposto intervalo do poço 2-AP-1-CE (Araripe estratigráfico $\left.\mathrm{n}^{\mathrm{o}} 1\right)$ como seção-tipo para a unidade [...]". Na realidade, Assine (1990, p. 56) escreveu: "[...] é recomendável enquadrar tais sedimentos como uma nova formação, para a qual propõe-se a denominação Formação Barbalha. Como seção-tipo para a unidade, foi escolhida a do Rio Batateiras (figura 31)[...]". Enquanto em Assine (1992, p. 296) lêse: "[...] é proposta a utilização da denominação Formação Barbalha (Assine, 1990) para a unidade, cuja seção-tipo (fig. 7) pode ser observada no Rio da Batateira, entre a cidade de Crato (CE) e as escarpas da Chapada do Araripe[...]". Já em Ponte \& Appi (1990, p. 5) lê-se: "[...] o nome deriva da seção-tipo, que aflora nos barrancos do Rio da Batateira [...]”. Portanto, além de atender ao princípio da prioridade, a denominação "Formação Rio da Batateira" apresenta a vantagem de referir-se ao nome geográfico da localidade onde se encontra a seção-tipo da unidade proposta, uma vez que, tanto Assine (1990, 1992) quanto Ponte \& Appi (1990), apontam os afloramentos ao longo do Rio Batateira como seção-tipo.

Uma questão que necessita de discussão relaciona-se ao posicionamento do limite entre as formações Rio da Batateira e Santana, pois, enquanto alguns autores assinalam esse limite na base da camada de calcários laminados (Assine 1992, 2007), outros consideram que a Formação Santana inclui a camada de folhelhos cinza escuro a negros encontrada abaixo dos calcários (Ponte \& Appi 1990). Quanto a esse ponto, deve-se considerar que: (a) Beurlen (1962, p. 365), ao propor a Formação Santana, indicou explicitamente a presença de "folhelho betuminoso" na base desse intervalo; (b) Beurlen (1963, p. 14), quando elevou o membro inferior dessa unidade ("calcários 


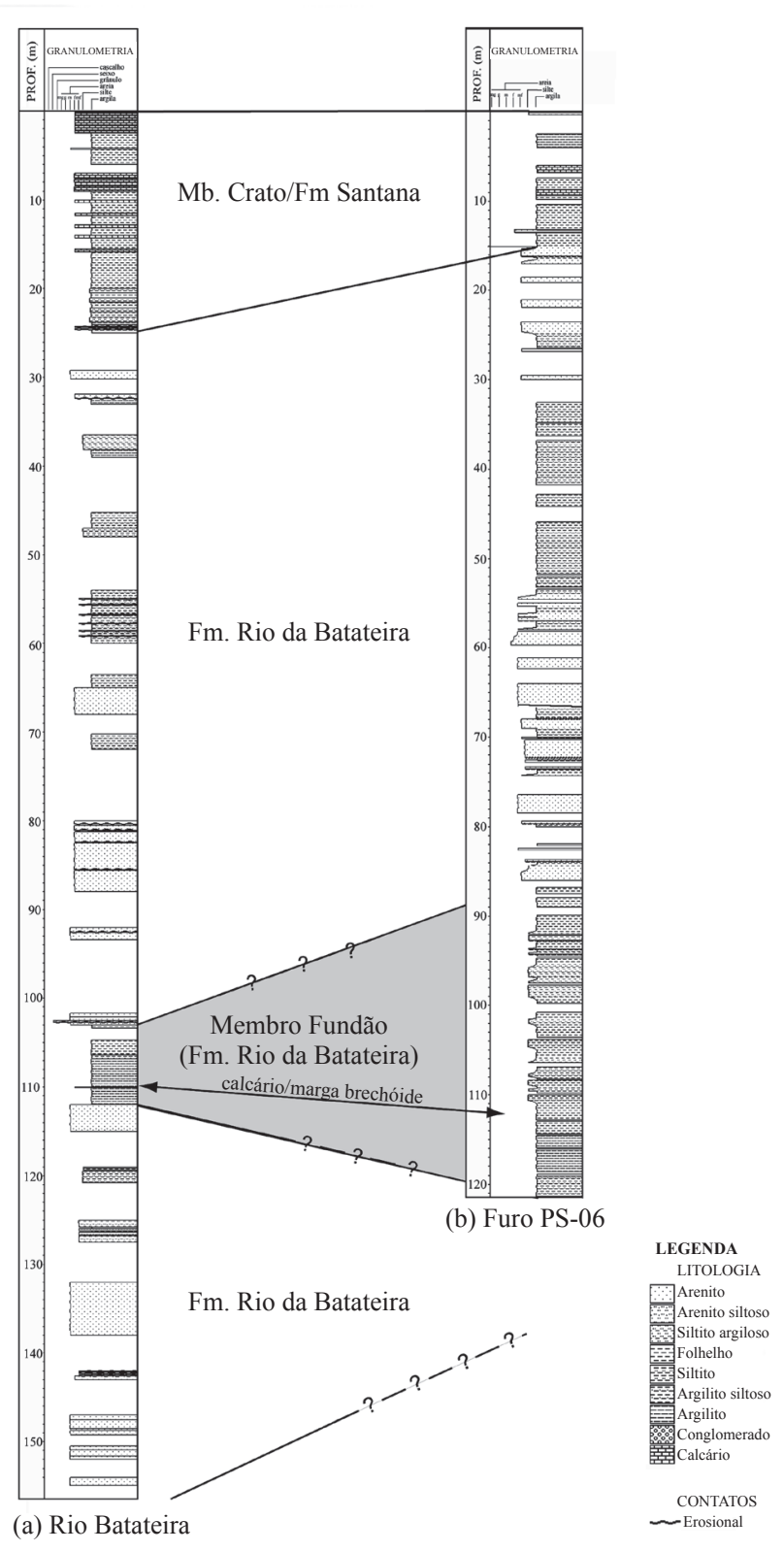

Figura 2 - (A) mostra perfil estratigráfico ao longo do Rio Batateira. O intervalo denominado "Membro Fundão" no presente trabalho corresponde àquele conhecido na literatura como "camadas Batateira". As profundidades assinaladas nesse perfil têm como referência o topo da cascata do Lameiro (profundidade $=0$ metros; cota altimétrica $=579$ metros; coordenadas: Zona 24M, $X=449824$, $Y=9198236$ ) e ponto final (profundidade $=155$ metros; cota altimétrica $=424$ metros; coordenadas: Zona 24M, $X=453329, Y=9201298$ ). (A) e (B) ilustram os estratótipos propostos para o Membro Fundão. (2A) holoestratótipo: intervalo entre as cotas altimétricas 467 metros (profundidade $=103 \mathrm{~m}$ ) e 476 metros (profundidade $=112 \mathrm{~m}$ ), no Sitio Fundão, na margem do rio Batateira, Crato, CE; (2B) estratótipo suplementar: intervalo entre as profundidades $86,20 \mathrm{e}$ 121,80 metros do furo de sondagem 1-PS-06-CE, na localidade de Salobro, Abaiara, Ceará. inferiores" de Beurlen, 1962) à categoria de formação ("Formação Crato"), informou que "[...] um leito betuminoso ocorre na região de Barbalha sempre na base da sequência[...]"; (c) são os folhelhos e argilitos cinza escuros a negros que dão homogeneidade à Formação Santana, que pode ser caracterizada como um intervalo com predominância dessa litologia, com intercalações de calcários laminados na porção inferior (Membro Crato), de gipsita na porção intermediária (Membro Ipubi) e de concreções calcárias na porção superior (Membro Romualdo). Conclui-se, portanto, que o limite entre aquelas formações deve ser marcado imediatamente acima dos arenitos levemente avermelhados da Formação Rio da Batateira e na base dos folhelhos cinza escuro a negros da Formação Santana (Fig. 2A).

Em relação à variação granulométrica, para Ponte \& Appi (1990) e Assine (1992), a unidade e a parte mais inferior da Formação Santana compõem dois ciclos de granodecrescência ascendente. Por outro lado, um estudo recente de Paula-Freitas (2010) reconhece, nesse mesmo intervalo, três sequências deposicionais, também com granodecrescência ascendente, limitadas por superfícies erosivas. A presença de ciclos ou sequências foi também reconhecida durante a realização do presente estudo. Em campo, observa-se que a seção-tipo da Formação Rio da Batateira (Fig. 2A) inicia-se com arenitos amarelados a levemente avermelhados, finos a médios, com estratificação cruzada e frequentes clastos de argila. Sobre eles, encontra-se um intervalo de folhelhos cinza escuro a negros, em cuja porção inferior encontra-se uma camada calcária de aspecto brechoide. Esse intervalo corresponde ao primeiro ciclo de Ponte \& Appi (1990) e à sequência 1 de Paula-Freitas (2010).

O subintervalo final desse ciclo/sequência, composto por folhelhos escuros com calcário brechoide, tem sido referido na literatura como "camadas Batateira". Uma superfície erosiva separa este pacote de folhelhos de outro ciclo/sequência composto por conglomerados e arenitos médios amarelados a levemente avermelhados, que passam a arenitos finos cinza, com intercalações de siltitos e argilitos vermelhos e folhelhos cinza claro, sendo que essas camadas de lutitos vermelhos ganham importância em direção ao topo da coluna. Novo contato erosivo separa os lutitos vermelhos de um breve intervalo de arenitos finos e 
argilitos cinza claro, após o qual encontra-se um grande pacote de folhelhos cinza escuro a cinza esverdeado, com significativas camadas de calcários laminados, que é correlacionado à parte inferior da Formação Santana (Membro Crato). O segundo ciclo de Ponte \& Appi (1990) seria marcado desde os conglomerados e arenitos médios até os folhelhos escuros e calcários laminados do Membro Crato. Esse intervalo, porém, conteria duas sequências, para Paula-Freitas (2010): a sequência 2 iria desde a primeira superfície erosiva, que separa os folhelhos escuros dos conglomerados e arenitos médios até a segunda superfície erosiva, que separa os lutitos vermelhos dos arenitos finos e siltitos cinza. A sequência 3 engloba os arenitos finos e siltitos, além dos folhelhos e calcários laminados do Membro Crato, tendo por limite superior uma terceira superfície erosiva, que não foi reconhecida no Rio Batateira.

Quanto à geocronologia, a Formação Rio da Batateira é considerada como sendo de idade Alagoas (Cretáceo Inicial), por Coimbra et al. (2002), o que seria indicado tanto por palinomorfos (Biozona P-270) quanto por ostracodes (Biozona NRT-011).

\section{As "camadas Batateira" Finalizando a se-} quência 1 da Formação Rio da Batateira (PaulaFreitas 2010), encontra-se um intervalo de folhelhos cinza escuro a negro, intercalado em arenitos (Figs. 2A e 3). No perfil do Rio Batateira, uma breve camada de calcário brechoide está presente na parte inferior desse pacote. Esse intervalo de folhelhos escuros ocorre, na mesma posição estratigráfica, tanto na Sub-bacia do Cariri (Farina 1974, Scheid et al. 1978), quanto na de Feitoria (Ponte \& Appi 1990, Portela 2008). Farina (1974) estudou esse intervalo e o denominou de "sequência plumbífera do Araripe", devido à mineralização em sulfetos de chumbo, zinco e cobre, que se encontra geralmente associada à camada intermediária de calcário ou marga. Essa mineralização ocorre pelo menos em toda a borda Noroeste da Bacia do Araripe, e foi o alvo principal dos projetos Santana I (Moraes et al. 1976) e II (Scheid et al. 1978).

Ao estudarem a coluna sedimentar exposta no Rio Batateira, Hashimoto et al. (1987) equivocadamente reconheceram somente parte daquele intervalo - uma camada calcária com feições de exposição e uma de folhelhos betuminosos sotoposta -, a qual denominaram informalmente "camadas Batateira". Um aspecto importante a ressaltar é que Hashimoto et al. (1987) apontaram as "camadas Batateira" como correlatas às camadas Trairi (atualmente Membro Trairi - Condé et al. 2007), da Bacia do Ceará, e às camadas Ponta do Tubarão, da Bacia Potiguar, conferindo a esse intervalo um caráter de marco estratigráfico regional. Provavelmente devido à facilidade de reconhecimento desse intervalo e ao potencial de correlação defendido por Hashimoto et al. (1987), o nome "camadas Batateira" foi largamente aceito pelos estudiosos da Bacia do Araripe. No entanto, uma leitura atenta da literatura em que esse nome é citado permite observar que, sem discussão ou redefinição formal, ele vem sendo aplicado em sentido mais amplo do que o originalmente utilizado por Hashimoto et al. (1987). Assim, trabalhos posteriores (Ponte 1992, Chagas et al. 2007, Assine 2007) têm tratado como "camadas Batateira" o intervalo de folhelhos negros a que Farina (1974) denominou "sequência plumbífera do Araripe".

Como aponta a literatura e pode facilmente ser comprovado em campo, esse intervalo como um todo (camadas de folhelhos betuminosos com espessura de alguns metros, com uma camada decimétrica de calcários/margas brechoides intercalada) corresponde à culminância de uma sequência granodecrescente ascendente, sendo claramente distinguível das camadas síltico-areníticas acima e abaixo dele, tanto nos perfis litológicos (Scheid et al. 1978, Assine et al. 2006, Chagas et al. 2007, Assine 2007, Moura 2007, Paula-Freitas 2010), quanto nos de raio gama (Scheid et al. 1978, Assine 2007), além de representar um evento paleoambiental importante. Portanto, é o conjunto do intervalo - e não somente a camada de calcários/ margas mais os folhelhos sotopostos, como fizeram Hashimoto et al. (1987) - que deve ser tratado como uma unidade litoestratigráfica. Uma síntese da ideia amplamente difundida sobre as "camadas Batateira" pode ser encontrada em Assine et al. (2006) e Chagas (2006): o intervalo seria caracterizado pela presença de folhelhos betuminosos, alto teor de carbono orgânico total - COT $(25 \%$ - suposta característica, a qual não foi confirmada no presente trabalho), correlação com a palinozona P-270 (Aptiano superior), poucos metros de espessura e grande extensão lateral, deposição em ambiente fluviolacustre, sob clima quente e semiárido, 
e possível proximidade com o mar. A influência marinha durante a deposição das "Camadas Batateira" também é defendida por Pons et al. (1990).

Deve-se ressaltar que tanto a hierarquia quanto o nome desse intervalo já foram alvos de questionamentos: Berthou (1994) opinou que as camadas Batateira provavelmente "[...] seriam mais tarde separadas como uma unidade particular [...]", e Berthou et al. (1994) propuseram a denominação "unidade Fundão", embora preferindo não decidir, naquele momento, se o intervalo deveria ser considerado uma formação ou um membro.

MATERIAL E MÉTODOS O perfil estratigráfico desenvolvido a partir de afloramentos ao longo do Rio Batateira, entre os bairros de Batateira e Lameiro, na cidade do Crato, Ceará, foi correlacionado com o do furo de sondagem 1-PS-06-CE apresentado por Paula-Freitas \& Borghi (2009). Essa sondagem foi realizada no município de Abaiara, Ceará, pela Companhia de Pesquisa de Recursos Minerais (CPRM) - Serviço Geológico do Brasil, por solicitação do Departamento Nacional da Produção Mineral (DNPM), em novembro de 1978, no âmbito do "Projeto Santana II" (Scheid et al. 1978). A localização do furo de sondagem e do local de afloramento das "camadas Batateira" pode ser vista na Fig. 1.

Foram realizadas análises de COT em nove amostras do furo 1-PS-06-CE e quatro do Rio Batateira. As amostras do furo 1-PS-06-CE também tiveram seu conteúdo palinológico analisado.

\section{CARACTERIZAÇÃO DO INTERVALO}

\section{Litoestratigrafia No Rio Batateira, as "ca-} madas Batateira" correspondem a um intervalo de cerca de $9 \mathrm{~m}$ de espessura, que se inicia aproximadamente na cota altimétrica de $467 \mathrm{~m}$, em contato brusco com siltitos e arenitos finos a médios da parte inferior da Formação Rio da Batateira. $\mathrm{Na}$ base desse pacote composto predominantemente de folhelhos cinza escuro a negros (Fig. 3), encontra-se uma breve camada (cerca de $40 \mathrm{~cm}$ ) de argilitos amarronzados; a aproximadamente 2 $\mathrm{m}$ da base, há um intervalo de aproximadamente $10 \mathrm{~cm}$ com intercalações descontínuas de calcário. Aproximadamente na cota altimétrica de 476 $\mathrm{m}$, um contato erosivo separa esse pacote de folhelhos escuros de um espesso intervalo de arenitos

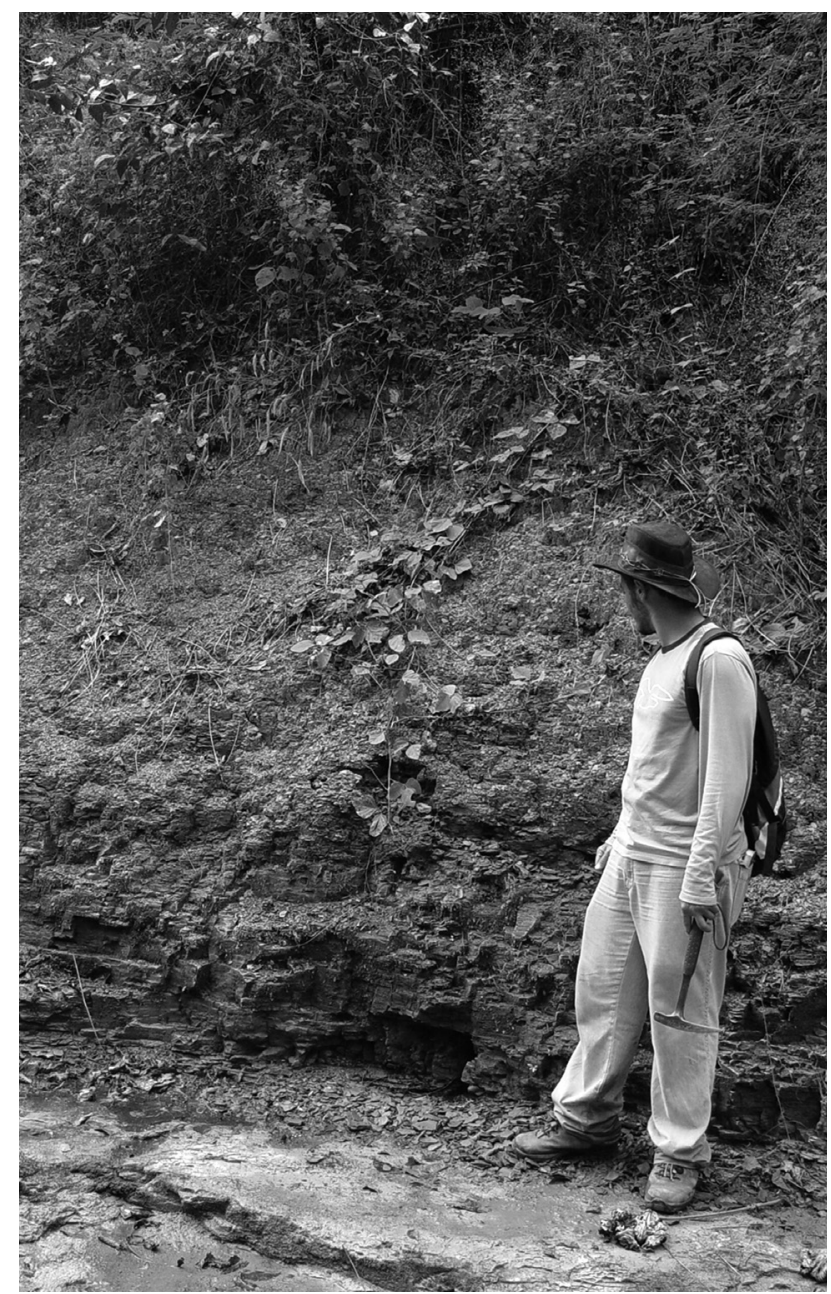

Figura 3 - Porção basal das "camadas Batateira", na margem do Rio da Batateira, Sitio Fundão, Crato, Ceará (coordenadas MC-39, Zona 24 M, X=451229, $Y=9200384$ ). Essa localidade foi apresentada como seção de referência por Hashimoto et al. (1987) e é proposta como parte de um estratótipo composto do Membro Fundão, no presente trabalho.

avermelhados, grossos a médios, com conglomerados na base, que corresponde à parte média da Formação Rio da Batateira.

No perfil estratigráfico do furo 1-PS-06$\mathrm{CE}$, as "camadas Batateira" atingem espessura de $35,6 \mathrm{~m}$, que se inicia na profundidade de $121,8 \mathrm{~m}$ com uma camada de aproximadamente $2,8 \mathrm{~m}$ de argilitos amarronzados. Entre as profundidades de 119,0 e $110,0 \mathrm{~m}$, encontram-se folhelhos de cor cinza a oliva. Scheid et al. (1978) apontam um nível de marga betuminosa mineralizada em enxofre entre as profundidades 112,60 e $112,53 \mathrm{~m}$. O restante do pacote $(110,0$ a $86,2 \mathrm{~m})$ é formado por folhelhos cinza a levemente amarronzados, com 
frequentes intercalações de siltitos, principalmente entre 110,0 e $91,5 \mathrm{~m}$ de profundidade. Na profundidade de $86,2 \mathrm{~m}$, encontra-se o contato brusco desse pacote de folhelhos com arenitos médios acinzentados da parte média da Formação Rio da Batateira.

Como pode ser observado, o intervalo conhecido como "camadas Batateira", geralmente descrito como pouco espesso (Hashimoto et al. 1987, Chagas 2006, Assine et al. 2006), alcança espessura bastante maior na localidade do furo 1-PS-06 -CE. Nota-se também que a parte superior desse intervalo - aquela ausente no Rio Batateira - é litologicamente menos homogênea, e a delimitação das "camadas Batateira" torna-se menos óbvia.

Palinologia Nove amostras foram coletadas no intervalo correspondente às "camadas Batateira" do furo 1-PS-06-CE, entre aproximadamente 119 e $86,2 \mathrm{~m}$. Os principais táxons presentes no intervalo são: Klukisporites variegatus, K. reticulatus, Cicatricosisporites microstriatus, C. avnimelechi, C. spp., Crybelosporites brenneri, Araucariacites australis, Classopollis brasiliensis, C. spp., Gnetaceapollenites spp., Afropollis aff. A. jardinus, Botryococcus spp. e palinomorfos retrabalhados do Paleozoico (por exemplo, Maranhites spp.). Apesar da ausência de Sergipea variverrucata, o conjunto da microflora sugere que o intervalo deve ser assinalado à Biozona P-270 de Regali et al. (1974), provavelmente à Subzona P-270.2 de Regali \& Santos (1999), confirmando-se idade aptiana final.

Em relação ao paleoambiente, a análise palinológica dessas amostras mostrou pico de aridez pouco acima da base do intervalo, registrado na profundidade de $113,5 \mathrm{~m}$, na qual o percentual de Classopollis é elevado (44,6\%), o de Araucariacites é bastante baixo $(3,1 \%)$ e o de esporos triletes, apesar de elevado $(43,0 \%)$, é mais baixo em relação às amostras imediatamente acima e abaixo desse nível. Nos demais níveis analisados, o percentual de Classopollis mantém-se relativamente baixo, aproximadamente constante (entre 10,1 e 19,5\%), enquanto, em direção ao topo, a frequência de esporos triletes apresenta uma tendência à diminuição $(74,5 \%$ na base, para 27,0\%, no topo) e a de Araucariacites apresenta valores elevados na parte média à superior (entre 30 e $40 \%$, aproximadamente). O conjunto das características litológicas e palinológicas (incluindo a presença de Botryococcus) indica deposição em ambiente lacustre proximal, raso. Não foram encontrados quaisquer palinomorfos indicativos de ambiente marinho.

Em relação ao paleoclima, esses resultados, mesmo sendo pontuais, mostram que o intervalo não pode ser considerado como sendo inteiramente depositado sob clima seco. O clima seria quente, oscilando entre relativamente úmido a seco, com pico de aridez correspondendo à proximidade do nível em que se depositaram os calcários brechoides.

Carbono orgânico total As nove amostras coletadas no intervalo, reconhecido como "camadas Batateira" do furo 1-PS-06-CE, apresentaram valores entre 0,4 e $0,79 \%$, sem tendência clara de diminuição ou aumento.

Foram analisadas quatro amostras coletadas nas "camadas Batateira" em afloramento do Rio Batateira. O teor mais elevado de COT $(9,9 \%)$ foi obtido na parte inferior do intervalo, nos argilitos negros intercalados em uma camada de calcários brechoides. As demais amostras do intervalo apresentaram teores entre 0,14 e $0,89 \%$.

Esses resultados contrariam a ideia, muitas vezes difundida, de que as "camadas Batateira" são caracterizadas por folhelhos ricos em COT (Assine et al. 2006). Embora eventualmente registrem-se altos percentuais de COT, principalmente próximo ao nível de calcários brechoides, esses não podem ser considerados característicos de todo o intervalo.

PROPOSTA DE FORMALIZAÇÃO Tendo em vista os dados apontados nesse trabalho e também o fato de que o intervalo em discussão, embora amplamente conhecido como "camadas Batateira", não foi formalizado por Hashimoto et al. (1987) ou por autores que lhes seguiram, considera-se que há necessidade de descrição e definição formais do intervalo, nos padrões do Código Brasileiro de Nomenclatura Estratigráfica (Petri et al. 1986a), conforme proposto a seguir.

Justificativa $\mathrm{O}$ intervalo analisado é claramente distinguível, em termos litoestratigráficos, das camadas que lhe são adjacentes e tem ampla distribuição na Bacia do Araripe. É comumente citado na 
literatura especializada sob denominação de "camadas Batateira" (Hashimoto et al. 1987, Berthou 1990, Ponte \& Appi 1990, Assine 1992, 2007, Martil \& Wilby 1993, Chagas 2006, Paula-Freitas \& Borghi 2009). No entanto, apesar das numerosas referências, esse intervalo nunca foi alvo de uma descrição formal. Em função do caráter informal, o termo "camadas Batateira" tem sido utilizado com abrangência variada entre os diversos autores, tornando-se urgente sua discussão e formalização.

Categoria da unidade Trata-se de uma unidade litoestratigráfica.

Hierarquia Membro. A atribuição da hierarquia de "membro" ao intervalo justifica-se por: sua relativa continuidade; sua extensão lateral, pois está presente na sub-bacia do Cariri (Farina 1974, Scheid et al., 1978, este trabalho) e, possivelmente, também na de Feitoria (Ponte \& Appi 1990, Portela 2008); sua espessura, que chega a $35 \mathrm{~m}$ no furo de sondagem 1-PS-06-CE.

Nome da unidade Propõe-se para o intervalo a denominação "Membro Fundão", opção que resgata o nome utilizado informalmente por Berthou et al. (1994). O termo "Batateira", utilizado por Hashimoto et al. (1987) para compor a designação informal "camadas Batateira", refere-se ao mesmo acidente geográfico (o Rio Batateira, na cidade do Crato, Ceará) que dá nome à Formação Rio da Batateira, unidade formalizada por Ponte \& Appi (1990) e da qual esse intervalo é parte integrante. Ora, o uso de um mesmo nome para uma unidade e para uma de suas partes contraria diretamente a orientação do Guia de Nomenclatura Estratigráfica (Petri et al. 1986b, p. 383). Além do argumento normativo, há o de propriedade: o termo "Batateira" tem como referência o rio ao longo do qual aflora quase toda a formação, sendo apropriado aplicá-lo àquela unidade, enquanto o termo "Fundão" refere-se, de modo mais restrito, à localidade do Sítio Fundão, na qual aflora, às margens daquele rio, especificamente o intervalo tratado como um membro. Assim, os argumentos apresentados sustentam a necessidade da mudança de denominação do intervalo e a propriedade do novo nome proposto.

Localidade-tipo A localidade na margem esquerda do Rio Batateira, na área conhecida como Sítio Fundão, município do Crato, Ceará (coordenadas MC-39, Zona $24 \mathrm{M}, \mathrm{X}=451229$ e $\mathrm{Y}=9200384)$ é definida como localidade-tipo do Membro Fundão. Para justificar essa escolha, considerou-se que: (a) os limites inferior e superior do Membro Fundão são facilmente reconhecíveis nessa localidade; (b) apesar de o Sítio Fundão não apresentar a parte superior da unidade, esta é a localidade onde o Membro Fundão está melhor representado em superfície; (c) apesar do caráter informal da proposta de Hashimoto et al. (1987), tal localidade é unanimemente citada na literatura especializada como seção de referência da unidade; e (d) a localidade é de fácil acesso.

De modo a garantir também a representação formal da parte superior do Membro Fundão, aponta-se como localidade-tipo suplementar a localidade de Salobro, município de Abaiara, Ceará (coordenadas MC-39, Zona $24 \mathrm{M}, \mathrm{X}=490500, \mathrm{Y}=$ 9187680), onde foi perfurado o furo de sondagem 1-PS-06-CE.

Estratótipo $\mathrm{O}$ intervalo entre as cotas altimétricas 467 e $476 \mathrm{~m}$, na margem esquerda do Rio Batateira, no Sítio Fundão, município do Crato, Ceará, foi escolhido como holoestratótipo (seção-tipo) do Membro Fundão. Na cota 467 m, encontra-se o limite inferior da unidade, um contato brusco entre o arenito médio, amarelado a levemente avermelhado, do topo da parte inferior da Formação Rio da Batateira, e argilitos amarronzados que logo passam a folhelhos cinza escuro, que constituem a base do Membro Fundão. Na cota 476 m, o topo do Membro Fundão é definido pelos arenitos grossos com estratificação cruzada passando a conglomerados, ambos de cor levemente avermelhada, e que compõem a parte média da Formação Rio da Batateira (Fig. 2).

Visando garantir a representação formal da parte superior do Membro Fundão, apontase como estratótipo suplementar o intervalo entre as profundidades 86,20 e $121,80 \mathrm{~m}$ do furo de sondagem 1-PS-06-CE. O limite superior da unidade, representado por folhelhos amarronzados (Membro Fundão) em contato com arenitos finos a médios acinzentados (base da parte superior da Formação Rio da Batateira), encontra-se na profundidade de $86,20 \mathrm{~m}$. O limite inferior não foi alcançado nesse furo de sondagem. Os testemunhos desse furo de sondagem estão depositados 
na sede do quarto distrito do DNPM, em Recife, Pernambuco.

Descrição O Membro Fundão é um intervalo argiloso, caracteristicamente posicionado entre os arenitos das porções inferior e média da Formação Rio da Batateira. A parte inferior do Membro Fundão inicia-se com argilitos amarronzados na base, passando rapidamente a folhelhos cinza escuro a negros, que se constituem na litologia predominante; em meio a esses folhelhos escuros, geralmente se observa uma camada calcária ou margosa, decimétrica, com níveis calcíferos descontínuos. A parte superior desse membro, de cor cinza a levemente amarronzada, é composta por folhelhos com frequentes intercalações de siltitos. O conteúdo fossilífero do Membro Fundão é formado de ostracodes, conchostráceos, coprólitos, palinomorfos e detritos algálicos e vegetais.

Espessura A maior espessura foi registrada no furo 1-PS-06-CE, com 35,6 m. No Rio Batateira, o intervalo restringe-se a $9 \mathrm{~m}$ de espessura.

\section{Correlação bioestratigráfica e idade}

Lima \& Perinotto (1984, 1985) estudaram uma amostra proveniente desse intervalo, na localidade de Carrancudo, município de Missão Velha, Ceará, e correlacionaram-no com o intervalo palinoestratigráfico P-260 a P-270, de Regali et al. (1974). Hashimoto et al. (1987) afirmaram que as "camadas Batateira" pertenceriam à Biozona P-270. Regali (2001) reavaliou os dados de Lima $\&$ Perinotto $(1984,1985)$ e considerou que a amostra estudada por eles estaria restrita à Biozona P-270. No presente trabalho, confirma-se que o intervalo deve ser atribuído à Biozona P-270, provavelmente à Subzona P-270.2, com idade aptiana final.

Observações O Membro Batateira é bastante útil na correlação litoestratigráfica intrabacial, especialmente se seu limite inferior - que é mais brusco - for usado como datum. No entanto, é pouco provável sua correlação direta com o Membro Trairi (Bacia do Ceará) e com as camadas Ponta do Tubarão (Bacia Potiguar), como proposto por Hashimoto et al. (1987) e corroborado por Condé et al. (2007), uma vez que: a característica de litologia, composta principalmente por folhelhos cinza escuros a negros, não é exclusiva desse intervalo, mas repete-se acima, em níveis da Formação Santana;

- a característica palinológica de intervalo caracterizado por alta concentração do gênero Classopolis não ocorre continuamente em todo ele, nem é exclusiva desse intervalo, mas repete-se acima, em níveis da Formação Santana;

- a característica geoquímica de intervalo caracterizado por alta concentração de COT não ocorre continuamente em todo o intervalo, nem é exclusiva desse intervalo, mas repetese acima, em níveis da Formação Santana;

- o conjunto dos parâmetros litológicos, palinológicos e geoquímicos analisados no presente trabalho indicam que o Membro Batateira foi depositado em ambiente lacustre proximal, não tendo sido encontrados quaisquer palinomorfos indicativos de ambiente marinho. Contrariamente, Condé et al. (2007) reafirmam deposição em ambiente marinho restrito para o Membro Trairi e Pessoa Neto et al. (2007) indicam que as camadas Ponta do Tubarão seriam o primeiro registro de ingresso marinho. Assim, a correlação desses intervalos deve ser buscada com níveis de folhelhos cinza escuros a negros, com picos de Classopollis e COT, da Formação Santana, à qual a literatura é unânime em apontar claramente a presença de elementos fósseis marinhos.

Ressalta-se que a formalização do Membro Fundão não altera a definição da Formação Rio da Batateira (Ponte \& Appi 1990), unidade da qual o intervalo é parte.

\section{CONCLUSÕES}

Os resultados das análises de COT realizadas nesse estudo (0,4 a $0,79 \%$, no furo 1-PS-06-CE; 0,14 a $0,89 \%$ em três amostras do Rio da Batateira, com pico de $9,9 \%$ em somente uma amostra) contrariam a ideia de que as "camadas Batateira" são sempre caracterizadas por folhelhos ricos em COT, embora eventualmente registrem-se altos percentuais de COT, principalmente próximo ao nível intermediário de calcários brechoides. 
O conjunto das características litológicas e palinológicas indica que o intervalo teria sido depositado em ambiente lacustre proximal, raso. Não foram encontrados quaisquer palinomorfos indicativos de ambiente marinho. O clima seria quente, oscilando entre relativamente úmido a seco, com pico de aridez correspondendo à proximidade do nível dos calcários brechoides.

Adenominação informal "camadas Batateira", atribuída por Hashimoto et al. (1987), foi considerada inválida, pois o intervalo estudado é parte integrante da Formação Rio da Batateira, unidade formalizada por Ponte \& Appi (1990) e cujo nome tem prioridade também sobre a denominação "Formação Barbalha”, proposto por Assine (1992). Propõe-se a denominação "Membro Fundão" para o intervalo.

O Membro Fundão alcança espessura considerável em alguns locais da Bacia do Araripe, como pode ser visto no furo de sondagem 1-PS-06 -CE (35,6 m).
Considerando-se o paleoambiente de deposição do Membro Batateira, é pouco provável sua correlação com o Membro Trairi (Bacia do Ceará) e com as camadas Ponta do Tubarão (Bacia Potiguar). Sugere-se que a correlação desses intervalos deve ser buscada, na Bacia do Araripe, com níveis da Formação Santana com características litológicas, micropaleontológicas e geoquímicas compatíveis.

\section{AGRADECIMENTOS}

Este estudo contou com o apoio do Conselho Nacional de Desenvolvimento Científico e Tecnológico (CNPq), da Fundação Carlos Chagas Filho de Amparo à Pesquisa do Estado do Rio de Janeiro (FAPERJ), Centro de Pesquisas Leopoldo Miguez de Mello (CENPES)/Petróleo Brasileiro S.A. (PETROBRAS) e da Fundação Coordenação de Projetos, Pesquisas e Estudos Tecnológicos (COPPETEC).

\section{Referências}

Assine M.L. 2007. Bacia do Araripe. Boletim de Geociências da Petrobras, 15(2):371-387.

Assine M.L. 1992. Análise estratigráfica da Bacia do Araripe, Nordeste do Brasil. Revista Brasileira de Geociências, 22(3):289-300.

Assine M.L. 1990. Sedimentação e Tectônica na Bacia do Araripe, Nordeste do Brasil. Programa de Dissertação de Mestrado, Pós-graduação em Geologia Regional, Instituto de Geociências e Ciências Exatas, Universidade Estadual Paulista/ Rio Claro, 124 p.

Assine M.L., Chagas D.B., Morales N., Freiras F.I., Araújo B.C. 2006. Camadas Batateira: um importante marco estratigráfico do Aptiano da Bacia do Araripe. In: SBG, Congresso Brasileiro de Geologia, 43, Anais..., 274 p.

Berthou P.Y. 1994. Critical analysis of the main publications about the stratigraphical framework of the Paleozoic and Mesozoic sedimentary deposits in the Araripe Basin (Northeastern Brazil). Simpósio sobre o Cretáceo do Brasil, 3, Boletim de Resumos, p. 123-126.

Berthou P.Y. 1990. Le bassin d'Araripe et les petits bassins intracontinentaux voisins (N.E. du Brésil); formation et evolution dans le cadre de l'ouverture de l'Atlantic Equatorial - comparaison avec lês bassins Ouest-Africains situés dans lê même contexte. In: Simpósio sobre a Bacia do Araripe e Bacias Interiores do Nordeste, 1, Atas, p. 113-134.

Berthou P.Y., Filgueira J.B., Sampaio J.J.A. 1994. From siliciclastic to carbonate sedimentation along the Rio da Batateira section (Araripe Basin, Crato, N.E., Brazil): type-sections description for "Fundão", "Rio da Batateira", and "Crato" lithostratigraphic units. In: Simpósio sobre o Cretáceo do Brasil, 3, Boletim de Resumos, p. 127-130.

Beurlen K. 1971. As condições ecológicas e faciológicas da Formação Santana, na chapada do Araripe (Nordeste do Brasil). Anais da Academia Brasileira de Ciências, 43 (suplemento):411-415.

Beurlen K. 1963. Geologia e estratigrafia da Chapada do Araripe. In: Congresso Nacional de Geologia, 17, Anais..., 47 p. (suplemento).

Beurlen K. 1962. A geologia da Chapada do Araripe. Anais da Academia Brasileira de Ciências, 34(3):365-370.

Braun O.P.G. 1966. Estratigrafia dos sedimentos da parte interior da região Nordeste do Brasil (Bacias do Tucano - Jatobá, Mirandiba e Araripe), Rio de Janeiro. Boletim do DGM/DNPM, 236.

Chagas D.B. 2006. Litoestratigrafia da Bacia do Araripe: Reavaliação e Propostas para Revisão. Dissertação de Mestrado, Programa de Pósgraduação em Geologia Regional, Instituto de 
Geociências e Ciências Exatas, Universidade Estadual Paulista/Rio Claro, 127 p.

Chagas D.B., Assine M. L., Freiras F.I. 2007. Fácies sedimentares e ambientes deposicionais da Formação Barbalha no Vale do Cariri, Bacia do Araripe, Nordeste do Brasil. Geociências, 26(4):313-322.

Coimbra J.C., Arai M., Carreño A.L. 2002. Biostratigraphy of Lower Cretaceous microfossils from the Araripe basin, northeastern Brazil. Geobios, 35(6):647-767.

Condé V.C., Lana C.C., Pessoa Neto O.C., Roesner, E.H., Morais Neto J.M., Dutra, D.C. 2007. Bacia do Ceará. Boletim de Geociências da Petrobras, 15(2):347-355.

Farina M. 1974. Sequência plumbífera do Araripe mineralização singenética sulfetada no Cretáceo sedimentar brasileiro. In: SBG, Congresso Brasileiro de Geologia, 28. Anais..., Sociedade Brasileira de Geologia, p. 61-76.

Hashimoto A.T., Appi C.J., Soldan A.L., Cerqueira J.R. 1987. O neo-Alagoas nas Bacias do Ceara, Araripe e Potiguar (Brasil); caracterização estratigráfica e paleoambiental. Revista Brasileira de Geociências, 17(2):118-122. Sociedade Brasileira de Geologia, São Paulo, Brasil.

Lima M.R. \& Perinotto J.A.J. 1985. Palinologia de sedimentos da parte superior da Formação Missão Velha, Cretáceo do Nordeste do Brasil. Anais da Academia Brasileira de Ciências, 57(1):117-118.

Lima M.R. \& Perinotto J.A.J. 1984. Palinologia de sedimentos da parte superior da Formação Missão Velha, Bacia do Araripe. Geociências, 3:67-76.

Martill D.M. \& Wilby P. 1993. Stratigraphy. In: Martill D.M. (ed.). Fossils of the Santana and Crato Formations, Brazil. The Palaeontological Association Field Guides to Fossils, 5:20-50.

Matos R.M.D. 1992. The Northeast Brazilian rift system. Tectonics, 11(4):766-791.

Moura M.V. 2007. Análise Estratigráfica do Andar Alagoas na Borda Leste da Bacia do Araripe. Dissertação de Mestrado, Programa de Pósgraduação em Geologia, Instituto de Geociências, Universidade Federal do Rio de Janeiro, 108 p.

Moraes J.F.S., Scheid C., Santos J.S.A. 1976. Projeto Santana: Relatório Final da Etapa I. Recife, DNPM/CPRM, 8 v.

Neumann V.H. \& Cabrera L. 1999. Una nueva propuesta estratigrafica para la tectonosecuencia post-rift de la Cuenca de Araripe, Noreste de Brasil. In: Simpósio Sobre o Cretáceo do Brasil, 5 / Simposio Sobre el Cretacico de America del Sur, 1, Boletim, p. 279-285.

Paula-Freitas A.B.L. 2010. Análise Estratigráfica do Intervalo Siliciclástico Aptiano da Bacia do
Araripe (Formação Rio da Batateira). Dissertação de Mestrado, Programa de Pós-Graduação em Geologia, Instituto de Geociências, Universidade Federal do Rio de Janeiro, 9 folhas, anexos.

Paula-Freitas A. B. L. \& Borghi, L. 2009. Gearquitetura em mega escala de um potencial reservatório siliciclástico aptiano na bacia do Araripe (Formação Rio da Batateira). In: 5 Congresso Brasileiro de pesquisa e desenvolvimento em petróleo e gás, 5 . Anais, arquivo 9762009.1.1.2, 9 p.

Pessoa Neto O.C., Soares U.M., Silva J.G.F., Roesner, E.H., Florêncio C.P., Souza C.A.V. 2007. Bacia Potiguar. Boletim de Geociências da Petrobras, 15(2):347-355.

Petri S., Coimbra A.M., Amaral G., Ojeda H.O., Fúlfaro V.J. Ponçano W.L. 1986a. Código Brasileiro de Nomenclatura Estratigráfica. Revista Brasileira de Geociências, 16:372-376.

Petri S., Coimbra A.M., Amaral G., Ponçano W.L. 1986b. Guia Brasileiro de Nomenclatura Estratigráfica. Revista Brasileira de Geociências, 16:376-415.

Pons D., Berthou P.Y., Campos D.A. 1990. Quelques observations sur la palynologie de l'Aptien Supérieur et de l'Albien du bassin d'Araripe (N.E. du Brésil). In: Simpósio Sobre a Bacia do Araripe e Bacias Interiores do Nordeste, 1, Atas, p. 241-252.

Portela H.A. 2008. Estudo Palinológico e Palinofaciológico da Formação Santana, Bacia do Araripe, Nordeste do Brasil. Dissertação de Mestrado, Faculdade de Geologia, Universidade do Estado do Rio de Janeiro, 133 p.

Ponte F.C. 1992. Sistemas deposicionais na Bacia do Araripe, Nordeste do Brasil. In: Simpósio sobre as Bacias Cretácicas Brasileiras, 2. Resumos Expandidos, p. 81-84.

Ponte F.C. \& Appi C.J. 1990. Proposta de revisão da coluna litoestratigráfica da Bacia do Araripe. In: SBG, Congresso Brasileiro de Geologia, 36, Anais..., 1:211-226.

Ponte F.C. \& Ponte-Filho F.C. 1996. Estrutura Geológica e Evolução Tectônica da Bacia do Araripe. Departamento Nacional de Produção Mineral/MME, Rio de Janeiro, Brasil, 68 p.

Regali M.S.P. 2001. Palinoestratigrafia dos sedimentos cretácicos da bacia do Araripe e das bacias interiores do Nordeste, Brasil. In: Barros L.M., Nuvens P.C. \& Filgueira J.B.M. 2001. Simpósio sobre a Bacia do Araripe e Bacias Interiores do Nordeste, 1 e 2. Comunicações, p. 101-108.

Regali M.S.P., Uesugui N., Santos A.S., 1974. Palinologia dos sedimentos meso-cenozóicos do Brasil (I). Boletim Técnico da Petrobras, Rio de Janeiro, 17(3):177-191. 
Regali M.S.P. \& Santos P.R.S. 1999. Palinoestratigrafia e geocronologia dos sedimentos albo-aptianos das Bacias de Sergipe e Alagoas - Brasil. In: Simpósio Sobre o Cretáceo do Brasil, 5 / Simposio Sobre el Cretacico de America del Sur, 1, Boletim, p. 411419.

Scheid C., Munis M.B., Paulino J. 1978. Projeto Santana: Relatório Final da Etapa II. Recife, DNPM/CPRM. $131 \mathrm{p}+$ ilust. e anexos.
Small H.L. 1923. Geologia e Suprimento d'Água Subterrânea no Ceará e Parte do Piauhy. Série I.D. Geologia, Publicação n. 25. Inspetoria de Obras Contra as Secas, 2a ed., 80p. (consultada a edição fac-similar publicada na Coleção Mossoroense, 88, de 1979).

Manuscrito ID:19573

Recebido em: 27/10/2010

Aprovado em: 07/03/2012 